\title{
Leap of Faith: Does Serum Luteinizing Hormone Always Accurately Reflect Central Reproductive Neuroendocrine Activity?
}

\author{
Suzanne M. Moenter \\ Department of Molecular and Integrative Physiology, Internal Medicine, and Obstetrics and Gynecology, \\ University of Michigan, Ann Arbor, Mich., USA
}

\section{Key Words}

Gonadotropin-releasing hormone · Luteinizing hormone ·

Kisspeptin · Neurokinin B P Pulse generator

\begin{abstract}
The function of the central aspects of the hypothalamic-pituitary-gonadal axis has been assessed in a number of ways including direct measurements of the hypothalamic output and indirect measures using gonadotropin release from the pituitary as a bioassay for reproductive neuroendocrine activity. Here, methods for monitoring these various parameters are briefly reviewed and then examples presented of both concordance and discrepancy between central and peripheral measurements, with a focus on situations in which elevated gonadotropin-releasing hormone neurosecretion is not reflected accurately by pituitary luteinizing hormone release. Implications for the interpretation of gonadotropin data are discussed.

๑) 2015 S. Karger AG, Basel
\end{abstract}

\section{Introduction}

A central neuronal component to the control of anterior pituitary function for the regulation of reproduction was appreciated long before hormones from either location could reliably be measured or were even completely identified. Hypophysectomy stopped female reproductive cycles and decreased libido. Replacement via the injection of pituitary extracts restored female cycles and libido [1]. A role for the hypothalamus was confirmed when electrical stimulation of this area was found to induce ovulation in female rabbits [2]. Rosalyn Sussman Yalow shared the Nobel Prize in Physiology and Medicine in 1977 for her work with Solomon Bernson to develop radioimmunoassays. Immunoassays opened a new world for endocrinology in which the dynamics of hormone release took a leading role because the sensitivity and relative simplicity of these methods made it possible to reliably analyze more frequent samples. In 1970, Dierschke et al. [3] published serum concentrations of luteinizing hormone ( $\mathrm{LH}$ ) released from the anterior pituitary of primates as a function of sample frequency, demonstrating the now classic sawtooth pattern of LH pulses. That paper concluded that the rhythmic pulsatile release of LH might be due to 'intermittent signals from the central nervous system'. This observation was made around the time the first hypothalamic releasing factors were being sequenced by brute force biochemistry. In 1971, Matsuo et al. [4] published the sequence of what is now called gonadotropin-releasing hormone $(\mathrm{GnRH})$, which is acknowledged to be the primary central factor regulating pituitary gonadotropin synthesis and release. Andrew V. Schally and Roger Guillemin, the heads of the laboratories that isolated the initial hypothalamic releasing factors for

\section{KARGER 125}

(c) 2015 S. Karger AG, Basel

0028-3835/15/1024-0256\$39.50/0

E-Mail karger@karger.com

www.karger.com/nen
Suzanne M. Moenter

Department of Molecular and Integrative Physiology

University of Michigan, 7725 Med Sci II, 1137 E. Catherine St

Ann Arbor, MI 48109-5622 (USA)

E-Mail smoenter@umich.edu 
Fig. 1. Administration of hourly pulses of $\mathrm{GnRH}$ maintains typical levels of both $\mathrm{LH}$ (closed symbols) and FSH (open symbols) in ovariectomized rhesus monkeys. In contrast, continuous GnRH suppressed both hormones within about a week. Adapted from Belchetz et al. [5] with permission from the AAAS.

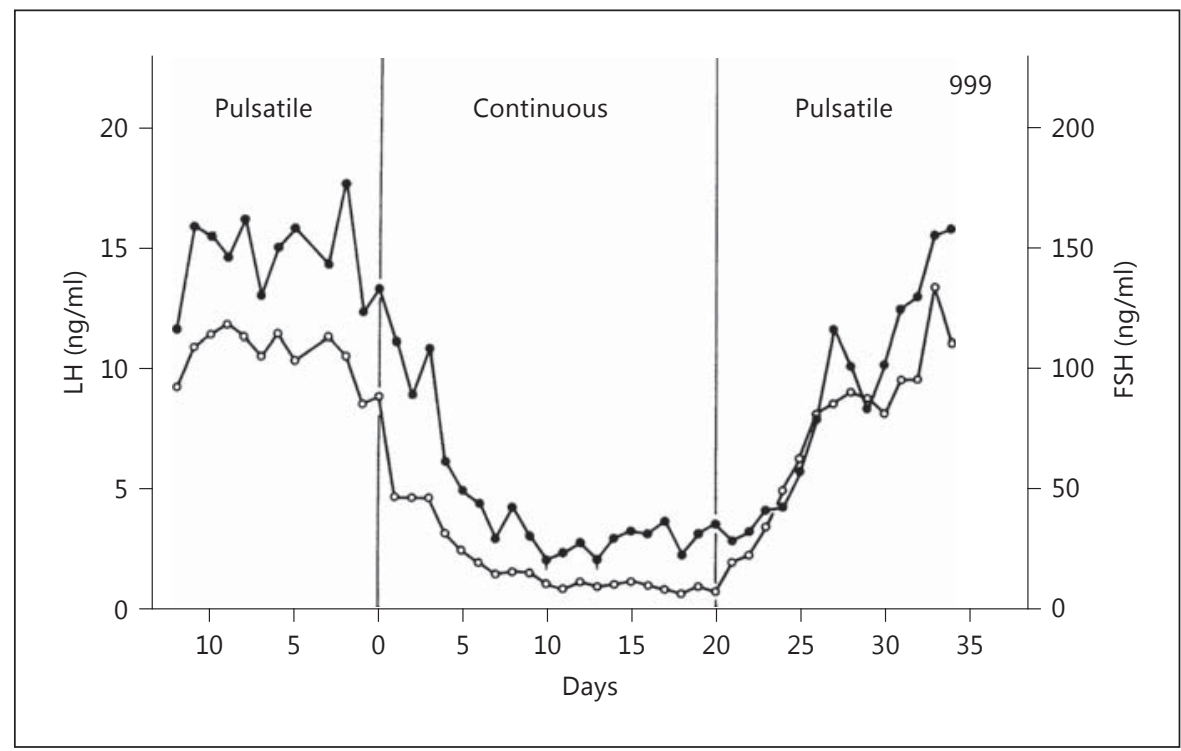

pituitary hormones, rounded out the Nobel Committee's selections for Physiology and Medicine in 1977.

Ernst Knobil and colleagues [5] conducted classic ablation/replacement studies that demonstrated the effects of pulsatile versus continuous $\mathrm{GnRH}$ on gonadotropin levels (fig. 1). In these studies, the medial basal hypothalamus was lesioned to eliminate endogenous $\mathrm{GnRH}$ release, and then $\mathrm{GnRH}$ was replaced intravenously in different patterns. The observations that the administration of $\mathrm{GnRH}$ in a continuous manner, rather than mimicking the presumed pulsatile release pattern, decreased circulating $\mathrm{LH}$ and follicle-stimulating hormone (FSH) levels within a few days, and that this decrease was reversible upon return to pulsatile administration, demonstrated the importance of the episodic nature of the central signal. This finding remains the basis for the current use of long-acting $\mathrm{GnRH}$ agonists to treat both precocious puberty and sex steroiddependent cancers [6-8] versus episodic administration for fertility restoration [9]. To this day, the generation of episodic hormone release in reproductive neuroendocrinology remains a topic of investigation and lively debate.

\section{Direct Monitoring of Central Neuroendocrine Activity}

The two methods most commonly used to directly monitor the activity of the central reproductive neuroendocrine system are multiunit activity (MUA) and sampling pituitary portal blood for GnRH (fig. 2). By the first method, MUA is measured using an array of electrodes deployed in a brain area of interest. The electrodes record action potential firing from several neurons in their vicinity, and peaks in this signal are generated when multiple neurons fire in a coordinated manner. MUA measurements, originally in the monkey [10] and subsequently in other species [11-14], demonstrated that peaks in neuronal activity within the medial basal hypothalamus were typically highly correlated with LH pulses. The phrase 'GnRH pulse generator' was coined to describe this neuronal activity. There are two drawbacks of MUA records, i.e. the inability to identify the cell type or types being recorded, and at least one degree of separation (release of GnRH itself) between the peaks in neuronal activity and the release of $\mathrm{LH}$.

The second method for directly monitoring reproductive neuroendocrine activity is measuring GnRH released into pituitary portal blood. Portal sampling bridges some of the gap between medial basal hypothalamic MUA and LH release by directly monitoring GnRH release. This technically difficult approach of accessing pituitary portal vessels is required because GnRH has a very short half-life due to enzymatic destruction in the blood; further, the small volume of portal blood is considerably diluted in the cavernous sinus and jugular blood. As such, GnRH cannot be measured in the peripheral circulation. This method was first applied in the rat $[15,16]$, but the small size of this species mandated the removal of the pituitary, precluding the simultaneous measurement of LH and limiting interpretable sampling to the periovulatory period, 


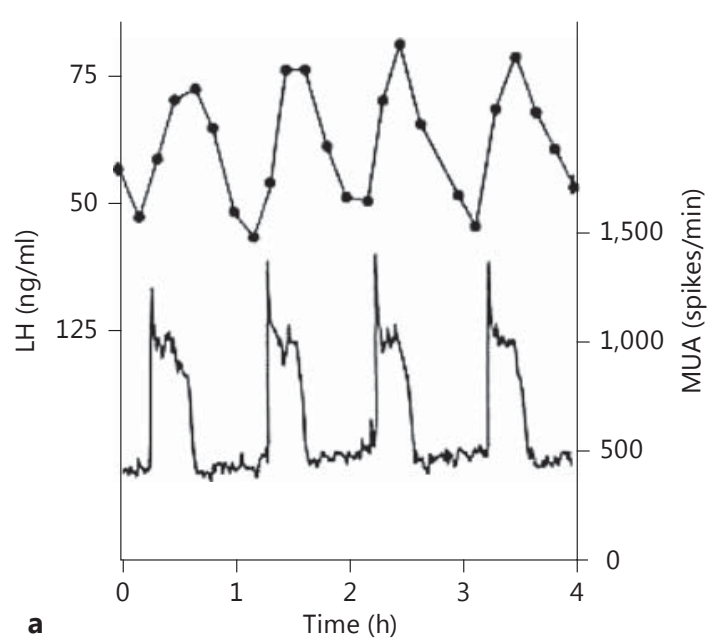

a

Fig. 2. Two methods for the direct monitoring of reproductive neuroendocrine activity. a MUA measurements in the infundibular region of an ovariectomized rhesus monkey; peaks in MUA directly precede LH pulses. Adapted with permission from O'Byrne et al. [28]. b Simultaneous sampling of pituitary portal blood from

when a large release of GnRH occurs. Sheep proved to be an excellent model for this approach; the large size allowed multiple simultaneous samples from both pituitary portal and jugular blood in fully conscious animals, permitting direct correlation of the two measurements within the same animal [17]. High-frequency sampling of portal blood suggested that GnRH release in sheep and MUA peaks in primates have a similar shape with a sharp onset to a peak, a high plateau below peak values, then a precipitous decline to baseline [18] (fig. 2). Portal sampling provides an excellent measure of the integrated output of $\mathrm{GnRH}$ at the median eminence; it is this GnRH release that regulates the pituitary gland. Of note, recent studies in in vitro preparations using methods that allow more localized monitoring of $\mathrm{GnRH}$ release have also identified secretion in the perisomatic region [19] and at the intersection of two GnRH neuronal processes [20]. GnRH released in these areas likely serves neuromodulatory functions that have been suggested in several studies [21-23], and may be under different regulatory control than neuroendocrine release of $\mathrm{GnRH}$ for pituitary regulation [24]. With regard to the neuroendocrine release of $\mathrm{GnRH}$, microdialysis and push-pull perfusion have also both provided more localized measurements of release near the median eminence [25-27]. The triple crown of simultane-

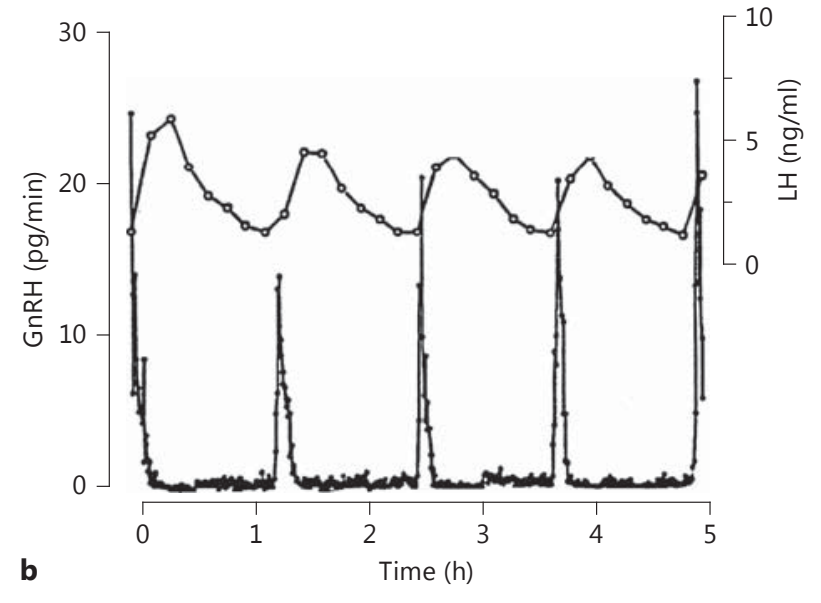

an ovariectomized sheep at 30-second intervals and jugular blood at 10-min intervals demonstrated a similar correlation between $\mathrm{GnRH}$ pulses and LH pulses. Adapted with permission from Moenter et al. [18]. These figures have been scaled so that the $\mathrm{x}-$ axis is the same to facilitate comparison.

ous recording of MUA peaks or other electrical activity, GnRH release and LH release remains unclaimed; however, the high correlation of the neuronal measurement, whether MUA or GnRH release, with LH pulses leads to the reasonable postulate that $\mathrm{LH}$ pulses can be used as a bioassay for central reproductive neuroendocrine activity.

\section{Matches and Mismatches between GnRH Release and LH Release}

In many biological states, the assumption that $\mathrm{LH}$ pulses reflect GnRH release patterns is likely a valid one. It remains, however, an assumption. Discrepancies between these measures can affect the interpretation of results based on observation of LH release alone.

\section{The Preovulatory GnRH Surge}

One such mismatch comes during the preovulatory period, when the action of sustained elevated levels of circulating estradiol from the mature follicle(s) triggers one of the rare positive feedback events in physiology, the preovulatory GnRH surge [16, 29-32]. Direct measurements of the GnRH surge in sheep indicate that it begins coincidently with the LH surge, but that it persists for a con- 

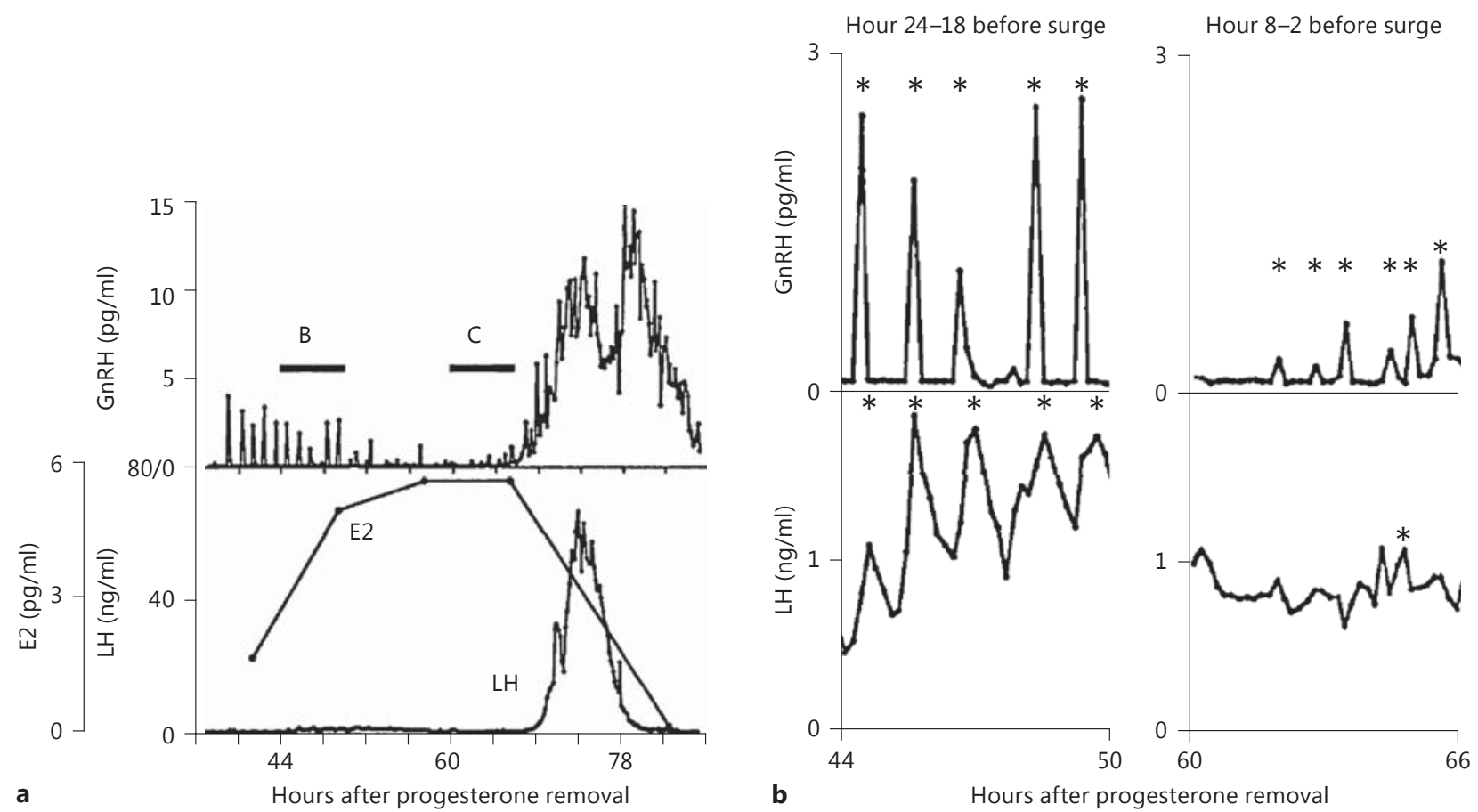

b

Hours after progesterone removal

Fig. 3. a GnRH (top), estradiol (E2) and LH (bottom) during an artificial follicular phase in sheep illustrating coincident onset of the GnRH and $\mathrm{LH}$ surges and prolonged duration of the former. $\mathbf{b}$, $\mathbf{c}$ Pulsatile GnRH (top) and LH (bottom) release from the periods indicated by the bars labeled B and C in $\mathbf{a} .{ }^{*}=$ Pulses. a-c Adapted with permission from Moenter et al. [32].

siderably longer duration (fig. 3a). Blockade of GnRH receptors before the onset of the surge or at different points during the LH surge eliminates or shortens the LH but not the $\mathrm{GnRH}$ surge, indicating that $\mathrm{GnRH}$ is a prerequisite for the duration of the LH surge [33]. Although the existence of a surge mode of GnRH release in humans remains a topic of debate [34-36], an estradiol-induced GnRH surge has been observed in rhesus monkeys [29], suggesting that at least some Old World primates exhibit this phenomenon; the presence of at least an episodic pattern of GnRH is acknowledged to be necessary for the generation of LH surges even in primates [37]. Of note, with regard to mismatches between $\mathrm{GnRH}$ and $\mathrm{LH}$, if a GnRH surge does not exist in humans, this would be an example of a mismatch in which a sustained LH increase is a false positive for increased central reproductive neuroendocrine activity.

Potential central roles for GnRH beyond its established action to induce the $\mathrm{LH}$ surge may provide insight into the extended nature of the $\mathrm{GnRH}$ versus the $\mathrm{LH}$ surge in sheep. Specifically, the duration of the GnRH surge is quite similar to that of proceptive sex behavior in ewes. This suggests a possible role for extended-duration $\mathrm{GnRH}$ release in mating. Indeed, the administration of $\mathrm{GnRH}$ antagonists after the $\mathrm{LH}$ surge is complete can reduce receptivity in ewes [21]. This additional biological action provides a physiological rationale for $\mathrm{GnRH}$ release that is unaccompanied by LH release. The time of ovulation appears more related to the onset of the $\mathrm{LH}$ surge [38], and ovulation does not require the full spontaneous LH surge [39], suggesting that it is initiated by a relatively short duration of exposure to LH. In contrast, the behavior needed to fertilize an oocyte requires continued exposure to $\mathrm{GnRH}$. These observations indicate that not all release from GnRH neurons is detected by monitoring pituitary hormone in the peripheral circulation, and that GnRH has additional roles beyond the regulation of gonadotropes.

\section{High-Frequency Episodic GnRH Release}

The clear mismatch in the duration of $\mathrm{GnRH}$ and $\mathrm{LH}$ release during the preovulatory surge is a once-a-cycle 


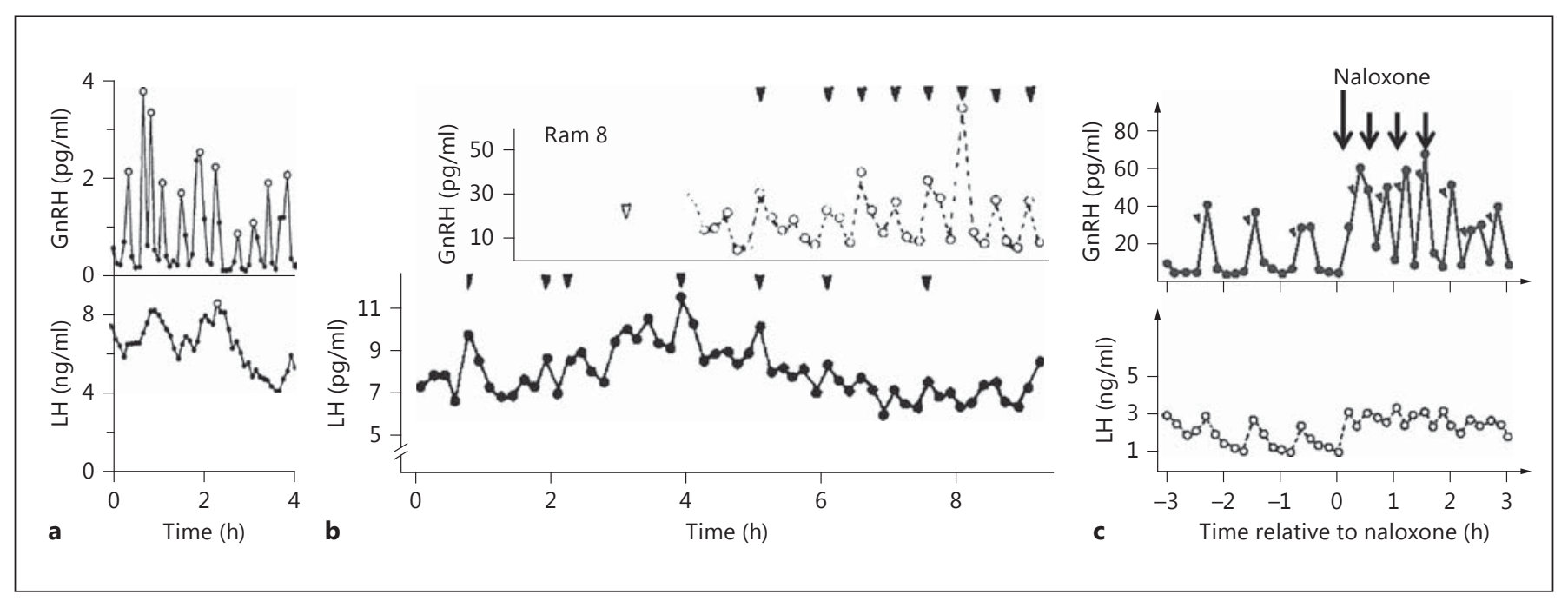

Fig. 4. LH is not always a reliable biomarker of high-frequency $\mathrm{GnRH}$ release. a GnRH (top) and LH (bottom) release in a thyroidectomized ewe. Open circles mark pulses detected by the cluster algorithm [46]. Adapted with permission from Webster et al. [43]. b GnRH (top) and LH (bottom) in a long-term castrate ram. The open arrowhead points to the time of portal vessel lesion for sam- pling; closed arrowheads mark detected pulses. Adapted with permission from Caraty and Locatelli [44]. c GnRH (top) and LH (bottom) release before, during and after treatment with naloxone (arrows; long arrow $100 \mathrm{mg}$, short arrows $50 \mathrm{mg}$ dose). Angled arrowheads mark detected pulses. Adapted with permission from Caraty et al. [45]. phenomenon in females, and is a quantitative rather than a qualitative change. Examples of mismatch when $\mathrm{GnRH}$ release is episodic and the examination of LH alone produces a qualitatively different interpretation about the central function may more substantially affect how we think about the hypothalamic-pituitary-gonadal axis. One example of this is illustrated in figure 3 [32]. During the midfollicular phase (fig. $3 \mathrm{~b}$ ), $5 \mathrm{GnRH} / \mathrm{LH}$ pulse pairs are evident. In contrast, during the late follicular phase just before surge onset, this relationship is less clear and LH release alone does not provide an accurate portrait of $\mathrm{GnRH}$ release (fig. 3c). There are several possible explanations for this. First, the amplitude of GnRH release is lower and may less effectively produce clear increases in $\mathrm{LH}$ that can be detected. Second, the GnRH release frequency is slightly higher, providing less time for the clearance of LH. The longer half-life of LH would preclude complete clearance from the circulation, thus obscuring pulses. Third, estradiol modifies the GnRH pulse shape [40], potentially altering pituitary responsiveness [41, 42 ]. Fourth, it is possible that the readily releasable pool of LH is depleted by high-frequency input. Finally, there is a possible technical reason, i.e. that the removal of a portion of portal blood for GnRH measurement may diminish the signal at the pituitary so that well-coordinated LH pulses are not produced. There are other examples in which a high-frequency, clearly episodic GnRH release is associated with circulating LH levels that do not reflect this activity, including thyroidectomized ewes (fig. 4a) [43], long-term castrate rams (fig. 4b) [44], and rams following treatment with the broad-spectrum opiate antagonist naloxone (fig. 4c) [45]. This last example is particularly compelling, because lower-frequency $\mathrm{GnRH}$ pulses are accompanied by clear LH pulses (time -3 to $0 \mathrm{~h}$; fig. 4c) in the same animal in which high-frequency $\mathrm{GnRH}$ is accompanied by an apparently apulsatile LH release. Unlike the example in figure $3 \mathrm{~b}$ and $\mathrm{c}$ above, the shift in GnRH frequency in response to naloxone in figure $4 \mathrm{c}$ is rapid, and the degradation of the $\mathrm{LH}$ pulse signal is not likely attributable to any of the above limitations of portal blood sampling. Taken together, these examples indicate that $\mathrm{LH}$ is not always a reliable biomarker when $\mathrm{GnRH}$ release frequency is high.

The most recent example of a possible mismatch between GnRH and LH release comes from a study of the development of GnRH release during the prenatal through adult period. This study used fast-scan cyclic voltammetry (FSCV) to monitor GnRH release in the median eminence in brain slices. This method takes advantage of the oxidation of $\mathrm{GnRH}$ on a carbon fiber microelectrode that can be positioned within a relatively discrete brain region [20]. A GnRH-specific signal was 


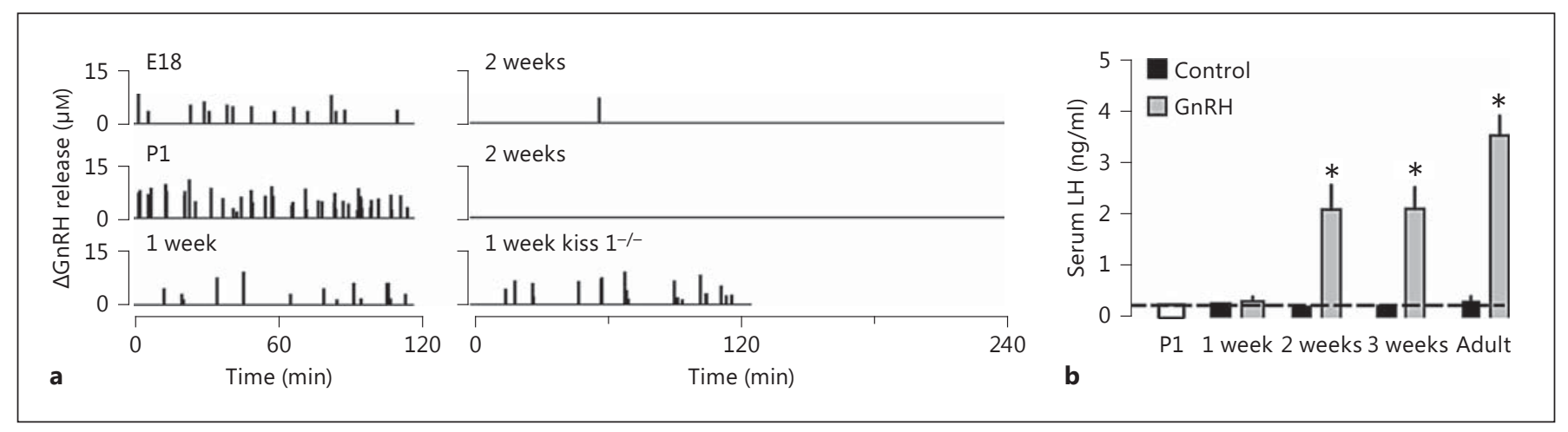

Fig. 5. High-frequency GnRH release during late prenatal and early postnatal development does not generate pituitary LH release. a Change in GnRH release in the median eminence at various ages. Vertical lines show GnRH release over time. $\mathbf{b}$ Serum $\mathrm{LH}$ in control mice and $15 \mathrm{~min}$ after injection of GnRH. Dashed line indicates sensitivity of the LH assay. ${ }^{*} \mathrm{p}<0.05$ relative to control of same age; P1 mice were not treated. Adapted with permission from Glanowska et al. [47].

detected with FSCV in the median eminence, and also in the preoptic area when electrodes were placed near the apposition of two identified GnRH fibers or that of a $\mathrm{GnRH}$ fiber and soma. No signal was detected in the median eminence of hypogonadal mice lacking $\mathrm{GnRH}$, demonstrating a specificity of this method for the GnRH decapeptide. Another recent study of cultured GnRH neurons also demonstrated release in the perisomatic region, using uptake of the fluorescent dye FM1-43 [19]. An advantage of these newer approaches is their ability to detect a release within very localized regions; a disadvantage is that both are currently accomplished in an in vitro preparation of either cultured cells (FM1-43) or acutely prepared brain slices (FSCV). This precludes simultaneous monitoring of $\mathrm{LH}$, introducing another potential caveat that must be considered. Of note in this regard, for adult male mice, the frequency of median-eminence GnRH release detected with FSCV in vitro [47] is similar to that of LH pulse frequency in vivo $[48,49]$.

When FSCV was used to monitor GnRH release frequency locally in the median eminence in brain slices made from mice aged from embryonic day 18 (E18) through postnatal week 1 , somewhat unexpected results were obtained (fig. 5) [47]. A very-high-frequency release was observed from E18 through 1 week of age $(\sim 5$ release events/h on E18, $\sim 15$ events/h within $24 \mathrm{~h}$ of birth, $\sim 5$ events/h at 1 week). The frequency then dropped to almost 0 by 2 weeks of age. The high-frequency release during the first week was further demonstrated to be vesicle mediated and independent of the neuromodulator kisspeptin. These observations were initially surprising, as
LH was undetectable at these ages, similar to previous observations [50-52], despite the pituitary expression of both the gonadotropin subunit genes and $\mathrm{GnRH}$ receptor [47]. Evaluation of LH release in vivo in response to a single injection of GnRH revealed no secretion at 1 week of age, when the GnRH release frequency was high in the median eminence, but a marked increase in response to $\mathrm{GnRH}$ at 2 weeks of age, when GnRH release was essentially absent. Although the pairing together of the in vitro $\mathrm{GnRH}$ and in vivo LH measures in different mice of the same ages must be done with caution, one possible explanation for these observations is that high-frequency endogenous GnRH release reduced the responsiveness of the pituitary gland with regard to LH release, which then recovered when the $\mathrm{GnRH}$ release frequency dropped about 2 weeks postnatally. Of interest, pituitary follistatin mRNA levels were elevated in control mice at 1 week of age, but declining thereafter [47]; follistatin mRNA is upregulated by high-frequency GnRH $[53,54]$, adding further evidence that the high GnRH frequencies observed in brain slices at this age may also be received in vivo by the pituitary gland and affect its function even though this is not reflected in $\mathrm{LH}$ release. The $\mathrm{LH}$ levels in mice through these stages of development suggest a physiological situation in which the GnRH frequency is sufficiently high to lead to pituitary shutdown, similar to both continuous GnRH (fig. 1) and high-frequency GnRH (3-5 pulses/h) in ablation/replacement studies [55].

In the above examples of pulsatile release, it is important to point out that the discrepancies are scenarios in which low LH does not accurately reflect high-frequency 
$\mathrm{GnRH}$, rather than low GnRH driving a disproportionately high LH release. While the relatively long half-life of LH clearly contributes to the obscuring of clear pulses in the circulation, there are other aspects to consider. These include changes in pituitary responsiveness to $\mathrm{GnRH}$ as well as other neuroendocrine and peripheral factors (e.g. steroids) that co-vary under these experimental conditions and may play important roles in sculpting the LH output. This could be achieved in part through changes in the GnRH receptor number or myriad postreceptor processes that are reviewed elsewhere [7, 56-59]. Increases in LH sample frequency may help clarify pulses in instances in which this variable is limiting, but in the examples shown this is typically adequate. Alternatively, the use of assays for the free $\alpha$-subunit, which has a much shorter half-life than the full LH dimer, may be another way to determine if it is the LH halflife alone that leads to a 'blurring' of the LH pulse pattern [60]. FSH, which has a longer half-life than LH, has been ignored for this discussion, as it would be even more problematic in terms of reflecting central neuroendocrine activity.

\section{If LH Does Not Always Reflect GnRH Release, Does the Observation of Low LH Levels Always Indicate a Lack of GnRH Release?}

This is a question that is critical to sculpting our interpretation of many studies in which $\mathrm{LH}$ is the primary variable measured. Direct measurement of central neuroendocrine activity remains difficult. The increasing use of genetic manipulations to probe further up the hypothalamic-pituitary-gonadal axis and study cells that are afferent to the GnRH neuron means that more steps occur between the manipulation and the release of LH. Further, many of these studies are done in small laboratory species because of the power of genetics, a trend that is likely to continue, since CRISPR/CAS9 methodologies make other species more accessible to genetic manipulation [61]. The small blood volume of many of these species means that investigators must attempt to interpret an episodic pattern of $\mathrm{LH}$, and thus GnRH release, from a limited number of samples. Together the biological 'distance' of the manipulation from LH measurement and the relatively low resolution of this measurement can contribute to potential inaccuracies in the interpretation.

Studies of the kisspeptin neuronal population in the arcuate nucleus serve to illustrate different ways to interpret the same data set. Arcuate kisspeptin neurons have

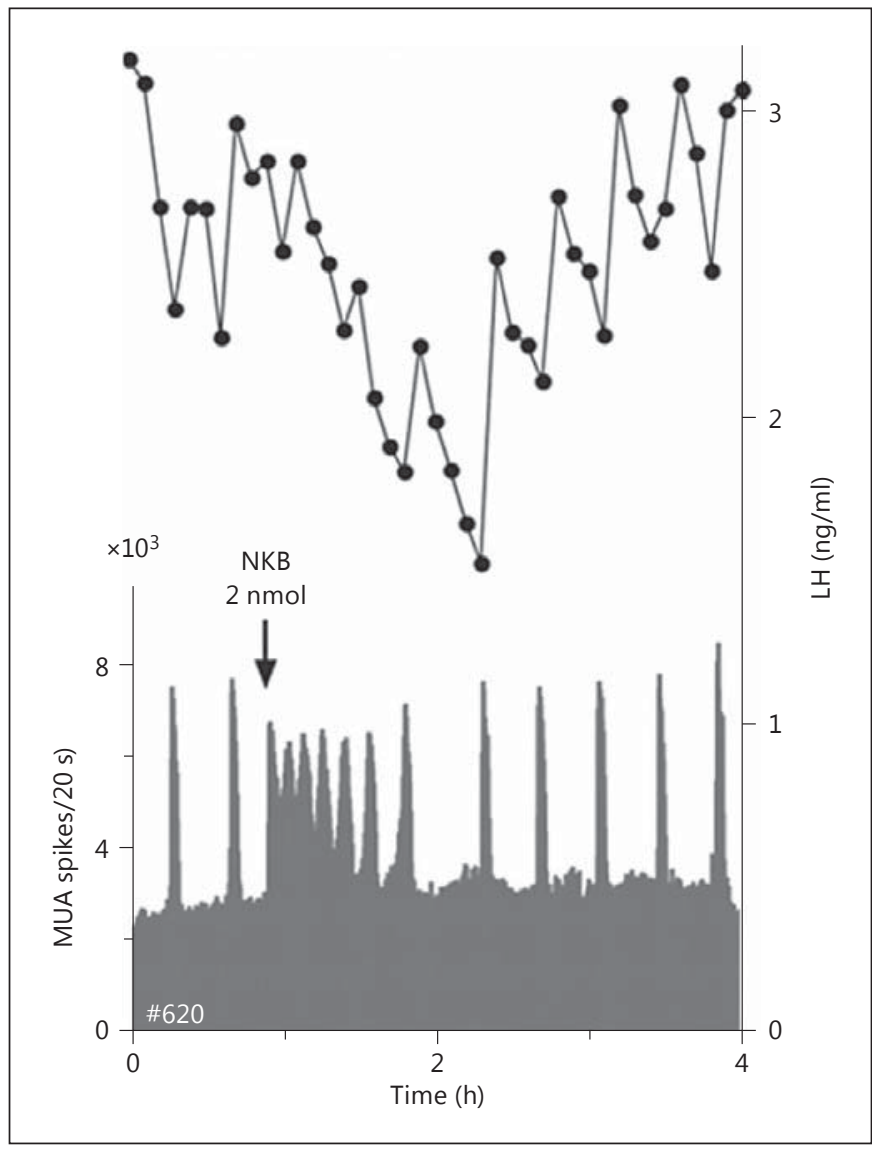

Fig. 6. Simultaneous measurements of MUA and LH reveal different directions of change. NKB increases the frequency of spikes of MUA but decreases serum LH levels. From Wakabayashi et al. [71] with permission.

been postulated to be the source of $\mathrm{GnRH}$ pulse generation $[62,63]$. These cells are also called KNDy neurons because of their coexpression of both neurokinin B (NKB) and dynorphin, two other neuromodulators thought to be important in fertility control. The anatomical connections of these cells with each other and with GnRH neurons - in combination with their expression of receptors for NKB and dynorphin but not kisspeptin receptors, which are expressed by GnRH neurons - have led to the following model. KNDy neurons act as an interconnected network that is activated by release of NKB and activation of neurokinin 3 receptors. This activation initiates kisspeptin release, which can induce $\mathrm{GnRH}$ release both at the soma and at the terminals $[24,64,65]$, with the latter release leading to increased $\mathrm{LH}$ secretion. The activation of KNDy neurons is also thought to initiate subsequent dynorphin release to terminate their increased activity, 
Fig. 7. Selective deletion of estrogen receptor-a from kisspeptin neurons causes early vaginal opening and elevated LH levels that subsequently return to control values but are not associated with estrous cyclicity. ${ }^{* *} \mathrm{p}<0.001 ;{ }^{* * *} \mathrm{p}<0.0001$. From Mayer et al. [73] with permission. $\mathrm{VO}=$ Vaginal opening; WT = wild type.

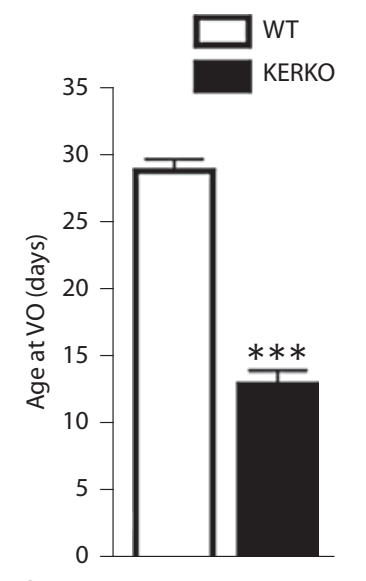

a

WT

b

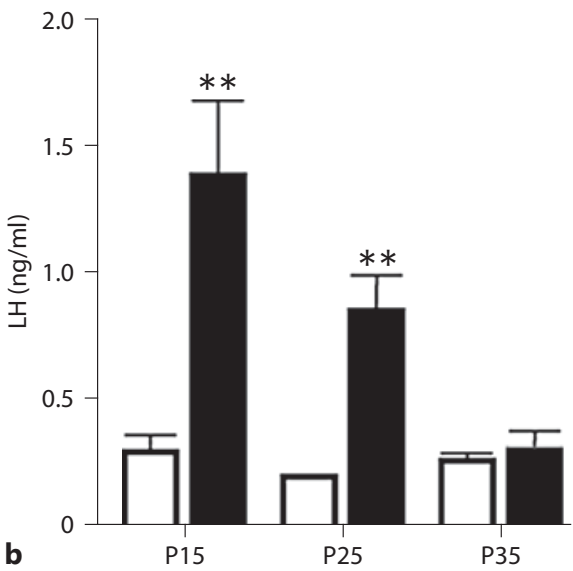

KERKO
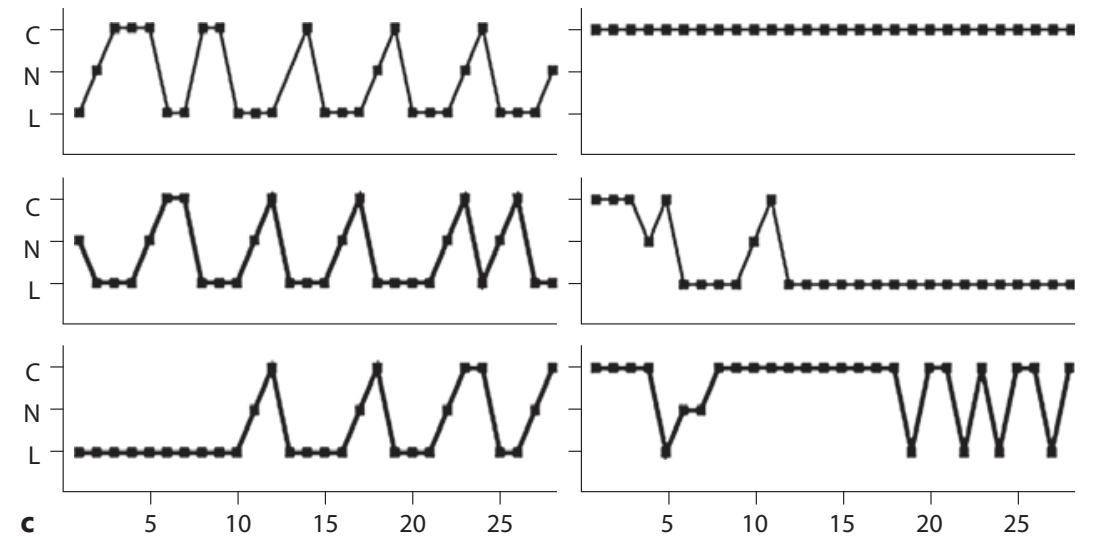

kisspeptin release and eventually GnRH release. Repeated cycles through this series of events would lead to episodic activation of GnRH neurons, hence a 'pulse generator'.

Many studies have tested various aspects of this model $\mathrm{GnRH}$ for pulse generation with a wide range of results depending on how the studies were done. For example, $\mathrm{NKB}$ and the neurokinin 3 receptor agonist senktide have been reported to increase, decrease or have no effect on LH release [66-70]. While differences in species and endocrine milieux can no doubt explain some of the range of results, it is also possible that a mismatch exists between central reproductive neuroendocrine actions and what the pituitary reports with LH release. Few studies have combined the administration of KNDy peptides with direct measures of central reproductive neuroendocrine output. One study in goats serves to illustrate different directions of movement of a central response (MUA) and LH release.
Wakabayashi et al. [71] monitored LH in response to NKB administered into the lateral ventricle of ovariectomized goats. NKB caused a decrease in LH levels and an apparent loss of the pulsatile pattern (fig. 6). If this had been the only measurement made, a logical conclusion would have been that NKB reduced GnRH release. GnRH itself was not measured in this study, but MUA peaks within the arcuate nucleus that were coincident with LH release were monitored. NKB caused a marked increase in the frequency of peaks in MUA spikes coincident with the drop in circulating LH. Thus, at least one central reproductive measure was increased despite the drop in LH. One possibility is that NKB activated KNDy neurons and this caused a large release of dynorphin, shutting down KNDy neurons and subsequent GnRH release. Another possibility is that NKB activated KNDy neurons, causing a large release of kisspeptin that induced GnRH release, but at 
such a high frequency that the pituitary output was blurred. Finally, it is possible that NKB itself directly activated GnRH release, which has been demonstrated to occur in male mice [72]. While these possibilities remain to be investigated, the simultaneous measurements of both the hypothalamic and pituitary levels of the axis opened the door to additional interpretations.

Another interesting example is from studies in which estrogen receptor- $\alpha$ was selectively deleted from kisspeptin-expressing neurons using targeted expression of cre recombinase, so-called KERKO mice [73]. Female KERKO mice exhibit early vaginal opening and elevated LH levels at 15 and 25 days of age, but no difference at 35 days of age (fig. 7). Despite similar single-point LH values, KERKO animals did not exhibit estrous cyclicity. Kisspeptin neurons are postulated to mediate steroid feedback to the GnRH system; thus the early vaginal opening and elevated LH levels appeared consistent with a loss of negative feedback leading to a precocious activation of GnRH release. But is the subsequent drop in $\mathrm{LH}$ due to eventual failure of the KNDy drive to GnRH neurons, or is it due to suppression of the pituitary in response to persistent high-frequency GnRH release? This question cannot be answered from the present data.

\section{Conclusion}

While LH clearly does not always accurately reflect central reproductive neuroendocrine activity, particularly when the central system is driven at a high frequency subsequent to experimental manipulation, for most physiologic measures, it remains a good bioassay. Exciting new genetic approaches make it possible to activate the central system to extents greater than typical physiology. These approaches are of value in trying to understand the neuronal networks underlying control of fertility, but high levels of central activation can add complexities that need to be considered. As the field implements these exciting new methodologies, one challenge is to make use of output measures that reflect, as much as possible, the nuanced patterning of the reproductive neuroendocrine system. Increased use of new low-volume assays for $\mathrm{LH}$ to monitor pulse patterns in mice [49], and optogenetic methods for activating central neuroendocrine pathways in vivo [74], may help in this regard. Moving genetic studies into larger species as CRISPR/CAS9 becomes more standard is another possible approach. While we need to be cautious in drawing absolute conclusions about the central function from examining only the pituitary output, interpretation of results should continue to be pushed to creative limits, so long as speculation is identified as such. Acknowledging multiple alternative mechanisms and interpretations does not diminish the importance of scientific findings. Rather, it strengthens its scholarly aspects and broadens thinking in the field.

\section{Acknowledgements}

This paper was supported by the National Institutes of Health/Eunice Kennedy Shriver National Institute of Child Health and Human Development (R01 HD34860, R01 HD41469, P50 HD28934). The author thanks Laura Burger, Eden A. Dulka, Carol F. Elias, Fred J. Karsch, Pei-San Tsai, Elizabeth Wagenmaker, Luhong Wang and Nancy L. Wayne for comments during manuscript preparation.

\section{References}

1 Smith PE: The disabilities caused by hypophysectomy and their repair: the tuberal (hypothalamic) syndrome in the rat. J Am Med Assoc 1927;88:158-161.

2 Harris GW: The induction of ovulation in the rabbit by electrical stimulation of the hypothalamo-hypophyseal mechanism. Proc Royal Soc Lond B 1937;122:374-394.

- 3 Dierschke DJ, Bhattacharya AN, Atkinson LE, Knobil E: Circhoral oscillations of plasma LH levels in the ovariectomized rhesus monkey. Endocrinology 1970;87:850-853.

-4 Matsuo H, Baba Y, Nair RMG, Arimura A, Schally AV: Structure of the porcine LH- and FSH-releasing hormone. I. The proposed amino acid sequence. Biochem Biophys Res Commun 1971;43:1334-1339.
5 Belchetz P, Plant TM, Nakai Y, Keogh EJ, Knobil E: Hypophysial responses to continuous and intermittent delivery of hypothalamic gonadotropin-releasing hormone. Science 1978;202:631-633.

6 Bertelloni S, Baroncelli GI: Current pharmacotherapy of central precocious puberty by GnRH analogs: certainties and uncertainties. Expert Opin Pharmacother 2013;14:16271639.

7 Millar RP, Pawson AJ, Morgan K, Rissman EF, Lu Z-L: Diversity of actions of GnRHs mediated by ligand-induced selective signaling. Front Neuroendocrinol 2008;29:17-35.

-8 Limonta P, Marelli MM, Mai S, Motta M, Martini L, Moretti RM: GnRH receptors in cancer: from cell biology to novel targeted therapeutic strategies. Endocr Rev 2012;33: 784-811.

9 Brodie TD, Crowley WF Jr: Neuroendocrine control of reproduction and its therapeutic manipulation with $\mathrm{GnRH}$ and its analogs. Int J Fertil 1985;30:66-70, 74-75.

10 Wilson RC, Kesner JS, Kaufman JM, Uemura T, Akema T, Knobil E: Central electrophysiologic correlates of pulsatile luteinizing hormone secretion in the rhesus monkey. Neuroendocrinology 1984;39:256-260.

-11 Mori Y, Nishihara M, Tanaka T, Shimizu T, Yamaguchi M, Takeuchi Y, Hoshino K: Chronic recording of electrophysiological manifestation of the hypothalamic gonadotropin-releasing hormone pulse generator activity in the goat. Neuroendocrinology 1991;53:392-395. 
$\checkmark 12$ Hiruma H, Nishihara M, Kimura F: Hypothalamic electrical activity that relates to the pulsatile release of luteinizing hormone exhibits diurnal variation in ovariectomized rats. Brain Res 1992;582:119-122.

13 O’Byrne KT, Knobil E: Electrophysiological approaches to gonadotrophin releasing hormone pulse generator activity in the rhesus monkey. Hum Reprod 1993;8:37-40.

14 Kinsey-Jones JS, Li XF, Luckman SM, O’Byrne KT: Effects of kisspeptin-10 on the electrophysiological manifestation of gonadotropinreleasing hormone pulse generator activity in the female rat. Endocrinology 2008; 149: 1004-1008.

15 Sarkar DK, Fink G: Luteinizing hormone releasing factor in pituitary stalk plasma from long-term ovariectomized rats: effects of steroids. J Endocrinol 1980;86:511-524.

-16 Sarkar DK, Chiappa SA, Fink G, Sherwood NM: Gonadotropin-releasing hormone surge in pro-oestrous rats. Nature 1976;264:461463.

17 Clarke IJ, Cummins JT: The temporal relationship between gonadotropin releasing hormone (GnRH) and luteinizing hormone (LH) secretion in ovariectomized ewes. Endocrinology 1982;111:1737-1739.

18 Moenter SM, Brand RM, Midgley AR, Karsch FJ: Dynamics of gonadotropin-releasing hormone release during a pulse. Endocrinology 1992;130:503-510.

19 Fuenzalida LC, Keen KL, Terasawa E: Colocalization of FM1-43, Bassoon, and GnRH-1: GnRH-1 release from cell bodies and their neuroprocesses. Endocrinology 2011;152: 4310-4321.

20 Glanowska KM, Venton BJ, Moenter SM: Fast scan cyclic voltammetry as a novel method for detection of real-time gonadotropin-releasing hormone release in mouse brain slices. J Neurosci 2012;32:14664-14669.

-21 Caraty A, Delaleu B, Chesneau D, Fabre-Nys C: Sequential role of $\mathrm{E} 2$ and GnRH for the expression of estrous behavior in ewes. Endocrinology 2002;143:139-145.

-22 DePaolo LV, King RA, Carrillo AJ: In vivo and in vitro examination of an autoregulatory mechanism for luteinizing hormone-releasing hormone. Endocrinology 1987;120:272279.

-23 Xu C, Xu XZ, Nunemaker CS, Moenter SM: Dose-dependent switch in response of gonadotropin-releasing hormone ( $\mathrm{GnRH})$ neurons to $\mathrm{GnRH}$ mediated through the type I GnRH receptor. Endocrinology 2004;145:728-735.

24 Glanowska KM, Moenter SM: Differential regulation of $\mathrm{GnRH}$ secretion in the preoptic area (POA) and the median eminence (ME) in male mice. Endocrinology 2015;156:231241.

25 Kenealy BP, Kapoor A, Guerriero KA, Keen KL, Garcia JP, Kurian JR, Ziegler TE, Terasawa E: Neuroestradiol in the hypothalamus contributes to the regulation of gonadotropin releasing hormone release. J Neurosci 2013; 33:19051-19059.
26 Watanabe G, Terasawa E: In vivo release of luteinizing hormone releasing hormone increases with puberty in the female rhesus monkey. Endocrinology 1989;125:92-99.

27 Sisk CL, Richardson HN, Chappell PE, Levine JE: In vivo gonadotropin-releasing hormone secretion in female rats during peripubertal development and on proestrus. Endocrinology 2001;142:2929-2936.

28 O'Byrne KT, Chen MD, Nishihara M, Williams CL, Thalabard JC, Hotchkiss J, Knobil E: Ovarian control of gonadotropin hormone-releasing hormone pulse generator activity in the rhesus monkey: duration of the associated hypothalamic signal. Neuroendocrinology 1993;57:588-592.

29 Xia L, Van Vugt D, Alston EJ, Luckhaus J, Ferin $\mathrm{M}$ : A surge of gonadotropin-releasing hormone accompanies the estradiol-induced gonadotropin surge in the rhesus monkey. Endocrinology 1992;131:2812-2820.

30 Clarke IJ, Thomas GB, Yao B, Cummins JT: GnRH secretion throughout the ovine estrous cycle. Neuroendocrinology 1987;46:82-88.

31 Moenter SM, Caraty A, Karsch FJ: The estradiol-induced surge of gonadotropin-releasing hormone in the ewe. Endocrinology 1990; 127:1375-1384

32 Moenter SM, Caraty A, Locatelli A, Karsch FJ: Pattern of gonadotropin-releasing hormone $(\mathrm{GnRH})$ secretion leading up to ovulation in the ewe: existence of a preovulatory $\mathrm{GnRH}$ surge. Endocrinology 1991;129:1175-1182.

33 Evans NP, Dahl GE, Caraty A, Padmanabhan V, Thrun LA, Karsch FJ: How much of the gonadotropin-releasing hormone $(\mathrm{GnRH})$ surge is required for generation of the luteinizing hormone surge in the ewe? Duration of the endogenous GnRH signal. Endocrinology 1996; 137:4730-4737.

34 Adams JM, Taylor AE, Schoenfeld DA, Crowley WF Jr, Hall JE: The midcycle gonadotropin surge in normal women occurs in the face of an unchanging gonadotropin-releasing hormone pulse frequency. J Clin Endocrinol Metab 1994;79:858-864.

35 Hall JE, Taylor AE, Martin KA, Rivier J, Schoenfeld DA, Crowley WF Jr: Decreased release of gonadotropin-releasing hormone during the preovulatory midcycle luteinizing hormone surge in normal women. Proc Natl Acad Sci USA 1994;91:6894-6898.

36 Kesner JS, Wilson RC, Kaufman JM, Hotchkiss J, Chen Y, Yamamoto H, Pardo RR, Knobil E: Unexpected responses of the hypothalamic gonadotropin-releasing hormone 'pulse generator' to physiological estradiol inputs in the absence of the ovary. Proc Natl Acad Sci USA 1987;84:8745-8749.

37 Knobil E, Plant TM, Wildt L, Belchetz PE, Marshall G: Control of the rhesus monkey menstrual cycle: permissive role of hypothalamic gonadotropin-releasing hormone. Science 1980;207:1371-1373.
38 Testart J, Frydman R: Minimum time lapse between luteinizing hormone surge or human chorionic gonadotropin administration and follicular rupture. Fertil Steril 1982;37:50-53.

39 Gosden RG, Everett JW: Luteinizing hormone requirements for ovulation in the pentobarbital-treated proestrous rat. Endocrinology 1976;99:1046-1053.

40 Evans NP, Dahl GE, Mauger D, Karsch FJ: Estradiol induces both qualitative and quantitative changes in the pattern of gonadotropinreleasing hormone secretion during the presurge period in the ewe. Endocrinology 1995; 136:1603-1609.

41 Perrett RM, Voliotis M, Armstrong SP, Fowkes RC, Pope GR, Tsaneva-Atanasova K, McArdle CA: Pulsatile hormonal signaling to extracellular signal-regulated kinase: exploring system sensitivity to gonadotropin-releasing hormone pulse frequency and width. J Biol Chem 2014;289:7873-7883.

42 McIntosh RP, McIntosh JE: Dynamic characteristics of luteinizing hormone release from perifused sheep anterior pituitary cells stimulated by combined pulsatile and continuous gonadotropin-releasing hormone. Endocrinology 1985;117:169-179.

43 Webster JR, Moenter SM, Barrell GK, Lehman MN, and Karsch FJ: Role of the thyroid gland in seasonal reproduction. III. Thyroidectomy blocks seasonal suppression of gonadotropin-releasing hormone secretion in sheep. Endocrinology 1991;129:1635-1643.

44 Caraty A, Locatelli A: Effect of time after castration on secretion of LHRH and LH in the ram. J Reprod Fertil 1988;82:263-269.

45 Caraty A, Locatelli A, Schanbacher B: Augmentation, by naloxone, of the frequency and amplitude of LH-RH pulses in hypothalamohypophyseal portal blood in the castrated ram. C R Acad Sci III 1987;305:369-374.

46 Veldhuis JD, Johnson ML: Cluster analysis: a simple versatile, and robust algorithm for endocrine pulse detection. Am J Physiol 1986; 250:E486-E493.

47 Glanowska KM, Burger LL, Moenter SM: Development of gonadotropin-releasing hormone secretion and pituitary response. J Neurosci 2014;34:15060-15069.

48 Coquelin A, Desjardins C: Luteinizing hormone and testosterone secretion in young and old male mice. Am J Physiol 1982; 243:E257-E263.

49 Steyn FJ, Wan Y, Clarkson J, Veldhuis JD, Herbison AE, Chen C: Development of a methodology for and assessment of pulsatile luteinizing hormone secretion in juvenile and adult male mice. Endocrinology 2013;154: 4939-4945.

50 Selmanoff MK, Goldman BD, Ginsburge BE: Developmental changes in serum luteinizing hormone, follicle stimulating hormone and androgen levels in males of two inbred mouse strains. Endocrinology 1977;100:122-127. 
-51 Prevot V, Rio C, Cho GJ, Lomniczi A, Heger S, Neville CM, Rosenthal NA, Ojeda SR, Corfas G: Normal female sexual development requires neuregulin-erbB receptor signaling in hypothalamic astrocytes. J Neurosci 2003;23: 230-239.

52 Michael SD, Kaplan SB, Macmillan BT: Peripheral plasma concentrations of $\mathrm{LH}, \mathrm{FSH}$, prolactin and GH from birth to puberty in male and female mice. J Reprod Fertil 1980; 59:217-222.

53 Kirk SE, Dalkin AC, Yasin M, Haisenleder DJ, Marshall JC: Gonadotropin-releasing hormone pulse frequency regulates expression of pituitary follistatin messenger ribonucleic acid: a mechanism for differential gonadotrope function. Endocrinology 1994;135:876880.

-54 Burger LL, Dalkin AC, Aylor KW, Haisenleder DJ, Marshall JC: GnRH pulse frequency modulation of gonadotropin subunit gene transcription in normal gonadotropes-assessment by primary transcript assay provides evidence for roles of $\mathrm{GnRH}$ and follistatin. Endocrinology 2002;143:3243-3249.

-55 Wildt L, Hausler A, Marshall G, Hutchison JS, Plant TM, Belchetz PE, Knobil E: Frequency and amplitude of gonadotropin-releasing hormone stimulation and gonadotropin secretion in the rhesus monkey. Endocrinology 1981;109:376-385.

56 Duran-Pasten ML, Fiordelisio T: GnRH-induced $\mathrm{Ca}^{2+}$ signaling patterns and gonadotropin secretion in pituitary gonadotrophs. Functional adaptations to both ordinary and extraordinary physiological demands. Front Endocrinol (Lausanne) 2013;4:127.

57 Thompson IR, Kaiser UB: GnRH pulse frequency-dependent differential regulation of LH and FSH gene expression. Mol Cell Endocrinol 2014;385:28-35.

58 Conn PM, Janovick JA: Trafficking and quality control of the gonadotropin releasing hormone receptor in health and disease. Mol Cell Endocrinol 2009;299:137-145.
59 Perrett RM, McArdle CA: Molecular mechanisms of gonadotropin-releasing hormone signaling: integrating cyclic nucleotides into the network. Front Endocrinol (Lausanne) 2013;4:180.

60 Hayes FJ, McNicholl DJ, Schoenfeld D, Marsh EE, Hall JE: Free alpha-subunit is superior to luteinizing hormone as a marker of gonadotropin-releasing hormone despite desensitization at fast pulse frequencies. J Clin Endocrinol Metab 1999;84:1028-1036.

61 Doudna JA, Charpentier E: The new frontier of genome engineering with CRISPR-Cas9. Science 2014;346.

62 Oakley AE, Clifton DK, Steiner RA: Kisspeptin signaling in the brain. Endocr Rev 2009;30:713-743.

63 Lehman MN, Coolen LM, Goodman RL: Minireview: kisspeptin/neurokinin B/dynorphin (KNDy) cells of the arcuate nucleus: a central node in the control of gonadotropinreleasing hormone secretion. Endocrinology 2010;151:3479-3489.

64 d'Anglemont de Tassigny X, Fagg LA, Carlton MBL, Colledge WH: Kisspeptin can stimulate gonadotropin-releasing hormone $(\mathrm{GnRH})$ release by a direct action at $\mathrm{GnRH}$ nerve terminals. Endocrinology 2008;149:3926-3932.

65 Messager S, Chatzidaki EE, Ma D, Hendrick AG, Zahn D, Dixon J, Thresher RR, Malinge I, Lomet D, Carlton MB, Colledge WH, Caraty A, Aparicio SA: Kisspeptin directly stimulates gonadotropin-releasing hormone release via $G$ protein-coupled receptor 54. Proc Natl Acad Sci USA 2005;102:1761-1766.

66 Navarro VM, Gottsch ML, Chavkin C, Okamura H, Clifton DK, Steiner RA: Regulation of gonadotropin-releasing hormone secretion by kisspeptin/dynorphin/neurokinin B neurons in the arcuate nucleus of the mouse. J Neurosci 2009;29:11859-11866.

67 Billings HJ, Connors JM, Altman SN, Hileman SM, Holaskova I, Lehman MN, McManus CJ, Nestor CC, Jacobs BH, Goodman RL: Neurokinin B acts via the neurokinin-3 receptor in the retrochiasmatic area to stimulate luteinizing hormone secretion in sheep. Endocrinology 2010;151:3836-3846.
68 Ramaswamy S, Seminara SB, Ali B, Ciofi P, Amin NA, Plant TM: Neurokinin B stimulates $\mathrm{GnRH}$ release in the male monkey ( $\mathrm{Ma}$ caca mulatta) and is colocalized with Kisspeptin in the arcuate nucleus. Endocrinology 2010;151:4494-4503.

69 Kinsey-Jones JS, Grachev P, Li XF, Lin YS, Milligan SR, Lightman SL, O'Byrne KT: The inhibitory effects of neurokinin B on GnRH pulse generator frequency in the female rat. Endocrinology 2012;153:307-315.

70 Corander MP, Challis BG, Thompson EL, Jovanovic $Z$, Loraine Tung YC, Rimmington $D$, Huhtaniemi IT, Murphy KG, Topaloglu AK, Yeo GS, O’Rahilly S, Dhillo WS, Semple RK, Coll AP: The effects of neurokinin B upon gonadotrophin release in male rodents. J Neuroendocrinol 2010;22:181-187.

71 Wakabayashi Y, Nakada T, Murata K, Ohkura S, Mogi K, Navarro VM, Clifton DK, Mori Y, Tsukamura H, Maeda K-I, Steiner RA, Okamura H: Neurokinin B and dynorphin A in kisspeptin neurons of the arcuate nucleus participate in generation of periodic oscillation of neural activity driving pulsatile gonadotropin-releasing hormone secretion in the goat. J Neurosci 2010;30:3124-3132.

72 Gaskins GT, Glanowska KM, Moenter SM: Activation of neurokinin 3 receptors stimulates $\mathrm{GnRH}$ release in a location-dependent but kisspeptin-independent manner in adult mice. Endocrinology 2013;154:3984-3989.

73 Mayer C, Acosta-Martinez M, Dubois SL, Wolfe A, Radovick S, Boehm U, Levine JE: Timing and completion of puberty in female mice depend on estrogen receptor a signaling in kisspeptin neurons. Proc Natl Acad Sci USA 2010;107:22693-22698.

74 Campos P, Herbison AE: Optogenetic activation of $\mathrm{GnRH}$ neurons reveals minimal requirements for pulsatile luteinizing hormone secretion. Proc Natl Acad Sci USA 2014;111: 18387-18392. 